\title{
Fundamentos Kantianos da Psicanálise Freudiana e o Lugar da Metapsicologia no Desenvolvimento da Psicanálise ${ }^{1}$
}

\author{
Leopoldo Fulgencio ${ }^{2}$ \\ Programa de Pós-Graduação em Psicologia da PUC Campinas
}

\begin{abstract}
Pretendo mostrar que as referências de Freud a Kant não dizem respeito a pontos ou temas específicos, mas, sim, que Freud construiu a psicanálise na tentativa de elaborar uma psicologia científica de acordo com o programa kantiano de pesquisa a priori para as ciências da natureza. Esse programa não só objetifica o psiquismo, tal como qualquer outra coisa estrangeira ao homem, naturalizando-o, como também propõe que esse objeto seja pesquisado com a ajuda de ficções heurísticas específicas - em especial, as que caracterizam a suposição de forças em conflito, que caracterizam o ponto de vista dinâmico -, as quais, em última instância, caracterizam a teorização de tipo metapsicológico na psicanálise. Tal quadro leva à pergunta sobre o futuro da psicanálise pósFreud, uma vez que o solo filosófico kantiano sofreu severas críticas com o desenvolvimento da filosofia pós-Kant.

Descritores: Freud, Sigmund, 1856-1939. Kant, Immanuel, 1724-1804. Filosofia da ciência. Metafísica. Psicanálise e filosofia.
\end{abstract}

\section{Freud e a metapsicologia como um conjunto de ficções heurísticas}

$\mathrm{F}$ reud considera que a grande contribuição da psicanálise para a ciência foi ter tomado "o espírito e a alma como objetos da pesquisa científica,

1 Artigo elaborado a partir de conferência apresentada no II Encontro Nacional de Filosofia da Psicanálise, realizado de 13 a 14 de novembro de 2006, na Faculdade de Filosofia da Universidade de São Paulo - USP. Este artigo corresponde a alguns dos resultados de minhas pesquisas de doutorado e pós-doutorado, financiadas pelo $\mathrm{CNPq}$ e pela FAPESP.

2 Membro do Departamento de Psicanálise do Instituto Sedes Sapientiae e do Centro Winnicott de São Paulo. Endereço eletrônico: ful@ that.com.br 


\section{Leopoldo Fulgencio}

exatamente da mesma maneira que não importa que outra coisa estrangeira ao homem" (Freud, 1933a, p. 159).

Nesse texto sobre a Weltanschauung ("visão de mundo"), ele também insiste no lugar da psicanálise como ciência, diferenciando-a da filosofia, da ideologia e, principalmente, de seu maior inimigo, a religião. Freud defendeu, do começo ao fim de sua obra, que a psicanálise fosse tomada como uma ciência empírica, uma ciência da natureza, não apenas por razões sociológicas, mas por razões epistemológicas que delimitam a natureza, sua dinâmica, os objetivos e os métodos para a apreensão dos fatos, a formulação de problemas e a procura das soluções que caracterizam essa disciplina.

É um fato teórico já estabelecido pela epistemologia (cf., por exemplo, Popper 1957), que não há ciência nem observação que não seja orientada e determinada por uma teoria prévia; mais ainda, que toda ciência (seja ela da natureza ou social) está construída sobre um conjunto de pressupostos. Já em Kant, encontramos a afirmação de que toda ciência depende de uma metafísica (Kant, 1786/1990, p. 15), seja esta da natureza ou dos costumes (cf. em Loparic 2003a uma análise dessas duas metafísicas em Kant).

Ao distinguir o que cabe à ciência e o que cabe à filosofia, convém ter em mente a diferença radical entre os problemas científicos e os problemas filosóficos, propriamente ditos. Mas, se, por um lado, a filosofia pode analisar criticamente os fundamentos metafísicos ou ontológicos sobre os quais uma ciência está edificada, por outro, uma ciência pode, por conta de seu próprio desenvolvimento, colocar problemas novos para a filosofia. Como diz Mach (1905), parece que a filosofia e a ciência caminham em sentidos inversos: "Sem dúvida, o que o filósofo toma como ponto de partida possível só aparece ao homem de ciência como o fim bem distante em direção ao qual tendem seus esforços" (March, 1905/1922, p. 15). No sentido inverso, parafraseando Mach: Sem dúvida, o que aparece ao homem de ciência como o fim bem distante em direção ao qual tendem seus esforços o filósofo toma como contribuição para que ele repense seus pontos de partida possíveis. Entre as duas disciplinas há, classicamente falando, um fosso... não são raros os cientistas e filósofos que sucumbiram ao saltar de uma à outra. 
Fundamentos Kantianos da Psicanálise Freudiana e o Lugar da Metapsicologia...

Ao tentar entender a relação entre Freud e Kant ${ }^{3}$, nota-se que o que está em jogo não é apenas a utilização que Freud fez de certos conceitos ou posições de Kant, tais como, para citar as referências mais centrais: as observações de Kant sobre o sonho e o estado de vigília, retomadas por Freud na Interpretação dos sonhos (1990); a referência ao inconsciente como sendo a coisa-em-si de Kant, na Interpretação dos sonhos e no artigo "O inconsciente" (1915b); na consideração do imperativo categórico como herdeiro direto do complexo de Édipo, em Totem e tabu (1911-12), nas lições de 1916-17 e no artigo "O problema econômico do masoquismo" (1924); a referência crítica às categorias apriorísticas espaço e tempo, que Kant atribui aos a priori da percepção e Freud credita aos a priori do pensamento, no artigo "Além do princípio do prazer" (1920). Também está em jogo algo mais estrutural para o pensamento de Freud, a saber: que a psicanálise freudiana, como uma psicologia empírica e uma ciência da natureza, foi construída no solo estabelecido pelo programa de pesquisa kantiano a priori para as ciências da natureza.

Essa não é uma tese propriamente nova. Heidegger, ao analisar o que Freud produziu como psicólogo, parece já ter referido essa relação, quando afirmou: "A metapsicologia de Freud é a transposição da filosofia neo-kantiana [da natureza] ao ser humano. Por um lado, ele [Freud] usa as ciências naturais e, por outro, a teoria kantiana da objetividade" (Heidegger, 2001 [1987], p. 222).

Caso Heidegger tenha razão e o kantismo de Freud possa ser confirmando, caberia, então, perguntar não mais propriamente sobre em quê foi que a psicanálise de Freud contribuiu para o desenvolvimento da filosofia, mas, sim, sobre o que é que a filosofia, especialmente a do século XX, produziu como crítica e ultrapassamento do kantismo, o que pode colocar questões para a psicanálise freudiana; ou, ainda, noutra direção, considerando que a psicanálise pós-Freud desenvolveu-se a ponto de reformular seus fundamentos metafísicos ou ontológicos, perguntar quais os desenvolvimentos da psicanálise pós-Freud que colocam questões para o desenvolvimento da filosofia.

Para que um diálogo efetivo, relativo a esse tema, possa ocorrer, é preciso que cheguemos a um acordo sobre o sentido de termos como metapsicologia, ficções heurísticas, especulações, método especulativo, pulsões,

3 Para uma apreensão crítica da totalidade das referências que Freud faz a Kant, ver Fulgencio (2001). 


\section{Leopoldo Fulgencio}

construções auxiliares, etc., sem o quê, uma ética da terminologia não seria respeitada e estaríamos jogados numa conversa entre surdos (algo tão comum na Babel psicanalítica atual) ou, como diz Freud: "sem o quê [...] nós cairíamos no papel ridículo que descreve Kant na sua célebre comparação na Crítica da razão pura, onde um homem segura a peneira sobre a barba de um bode enquanto um outro tenta ordenhá-lo" (Freud, 1911, p. 34).

Com base nisso, vou retomar alguns dos conceitos fundamentais da teoria psicanalítica freudiana, tal como Freud os caracteriza, tanto em termos da sua importância metodológica quanto da natureza epistemológica, para, em seguida, explicitar o programa de pesquisa kantiano, com vistas a mostrar que Freud construiu a psicanálise de acordo com o esse programa.

Ao referir-se ao aparelho psíquico, Freud diz: "A psicanálise supõe um postulado fundamental que pertence à filosofia discutir, mas cujos resultados justificam o valor" (Freud, 1940, p. 144). Esse postulado refere-se àquilo que Freud supõe existir entre o órgão somático do psiquismo e as atividades da consciência (1940, p. 144). Para Freud, a construção da psicologia deve tanto manter-se estritamente no campo da psicologia - evitando fazer uma psicologia utilizando termos fisiológicos, tal como parece ser a razão de seu abandono do Projeto, de $1897^{4}$ - quanto atender à necessidade epistemológica de tomar o psiquismo como um objeto, o que ele faz por meio de uma construção auxiliar, figurando esse objeto cujo acesso empírico direto lhe é negado pela própria constituição dele. Assim, as propostas de uma fiç̧ão teórica (1900, p. 603), tal como a do aparelho psíquico, convergem para uma proposição metodológica e metapsicológica, uma vez que o aparelho psíquico, por exemplo, está para além daquilo que uma psicologia dos fatos dispõe como acessível aos órgãos dos sentidos (sejam os sentidos externos, seja o sentido interno).

Em 1915, no texto que abre o conjunto dos ensaios metapsicológicos, Freud esclarece a função dessas construções auxiliares (ou idéias abstratas), dizendo que elas servem para apreender, organizar e dar inteligibilidade a seu material empírico (aquilo que ele pode observar diretamente em seus pacientes). ${ }^{5}$

4 Sobre a separação que Freud faz entre a psicologia e a fisiologia, em termos metodológicos, veja Lipps (2001) e os comentários de Loparic (2001; 2003b). Sobre o Projeto como uma metáfora, veja Fulgencio (2004).

5 Freud diferencia a psicanálise de outras psicologias justamente por causa de seu ponto 
Fundamentos Kantianos da Psicanálise Freudiana e o Lugar da Metapsicologia...

No texto "As pulsões e seus destinos" (1915a), Freud considera que o conceito de pulsão ou força de natureza psíquica é um fundamento de sua ciência, ainda que não seja um conceito muito claro; na verdade, é uma convenção (p. 117), que ele chega mesmo a caracterizar como um tipo de mitologia (Freud, 1933a, p. 95; 1933b, p. 211).

Já em 1894, no texto "As neuropsicoses de defesa", Freud havia dito que a utilização da hipótese auxiliar de um quantum de afeto, pensado de forma análoga a um fluído ou uma energia elétrica, pode levar a compreender a histeria, a neurose obsessiva e a fobia como patologias que, mesmo tão diferentes nas suas expressões, podem ser agrupadas por terem um mesmo tipo de dinâmica. Em todas elas, trata-se de uma energia que se desloca à procura de descarga, diferenciando-se, em cada uma, o caminho e o destino dessa procura: na histeria, esse quantum acaba por investir o corpo ou alguma parte dele; na neurose obsessiva, ele é dirigido para o pensamento e, na fobia, é enviado ao mundo externo. Note-se que Freud comenta, no final do artigo, a natureza epistemológica desse tipo de conceito auxiliar:

Para terminar eu quero lembrar, em poucas palavras, a representação auxiliar da qual me servi nesta exposição das neuroses de defesa. É a seguinte: nas funções psíquicas, cabe distinguir algo (montante de afeto, soma de excitação) que tem todas as propriedades de uma quantidade - ainda que não haja meio algum de medi-la -; algo que é suscetível de aumento, diminuição, deslocamento e descarga, e que se difunde pelas marcas mnêmicas das representações, como faria uma carga elétrica pela superfície dos corpos.

Pode-se utilizar essa hipótese, que por outro lado já se encontra no fundamento de nossa teoria do "ab-reagir" (Comunicação provisória, 1893) no mesmo sentido daquele que utilizam os físicos fazendo a hipótese da corrente de um fluído elétrico. Ela é justificável, provisoriamente, porque ela é útil para reagrupar e explicar os diversos estados psíquicos. (Freud, 1894a, p. 60)

Ao caracterizar o aparelho psíquico como uma ficção teórica, a pulsão como um conceito convencional e a libido como uma construção auxiliar apenas teórica, Freud também está afirmando que esses conceitos não são empíricos, ou seja, que eles não têm um referente na intuição - tal como acontece

de vista dinâmico: "[a psicanálise] propõe, no lugar de uma simples descrição, uma explicação dinâmica fundada sobre a interação de forças psíquicas” (Freud, 1913, p. 207). 


\section{Leopoldo Fulgencio}

com os conceitos de sexualidade infantil, complexo de Édipo, transferência, entre outros.

Enquanto caberia ao filósofo Freud a tarefa de discutir esses fundamentos especulativos da psicanálise em sua natureza última, ao cientista Freud caberia verificar se tais conceitos são ou não úteis para dar conta de seu material empírico, avaliando-os como corretos ou incorretos em função dos resultados obtidos, ou seja, em função da resolução dos problemas que eles permitem levar a cabo. É nesse sentido que Freud pode ser lido como defensor do ponto de vista heurístico na prática científica.

Ao referir-se à metapsicologia como um dos aspectos teóricos da psicanálise, Freud diz: "Eu proponho que se fale de uma apresentação metapsicológica quando nós conseguimos descrever um processo psíquico segundo suas relações dinâmicas, tópicas e econômicas" (Freud, 1915b, p. 182). Ou seja, para Freud, a metapsicologia, nesse sentido, é um conjunto de conceitos que ajudam a descrever os fenômenos psíquicos segundo três pontos de vista especulativos: o dinâmico, que toma o psiquismo como sendo movido por forças psíquicas em oposição, que ele denominou pulsões; o econômico, que supõe uma energia psíquica de natureza sexual, que ele caracterizou inicialmente como um quantum de afeto e, mais tarde, como libido; e o tópico, que toma o psiquismo como se fosse um aparelho dividido em instâncias psíquicas, espacialmente figuráveis (cf. Freud, 1915b, p. 182).

Freud está ciente desse fato, tanto que, em 1925, no seu estudo autobiográfico, diz:

Estas representações [aparelho psíquico dividido em instâncias], e outras similares, pertencem a uma superestrutura especulativa [spekulativer Überbau] da psicanálise, em que cada parte pode ser sacrificada ou trocada sem dano nem remorso, a partir do momento em que uma insuficiência é constatada. (Freud, 1925, pp. 32-33)

Noutro lugar, analisei com mais detalhes não só a natureza como a função da teoria metapsicológica na psicanálise, chegando à seguinte conclusão:

a metapsicologia não pode explicar os fenômenos clínicos nem constituir o sentido, ou parte do sentido, desses fenômenos, caso a palavra fenômeno seja tomada de acordo com o uso habitual, designando algo acessível à experiência clínica. A sua função é a de auxiliar a organização dos fatos, tornando possível estruturá-los 
Fundamentos Kantianos da Psicanálise Freudiana e o Lugar da Metapsicologia...

e relacioná-los; ela é um construto para conectar as descrições e uma orientaçãoguia para procurar (observar) novos dados. As especulações metapsicológicas não são nem fornecem explicações, mas estabelecem um quadro e uma direção para a busca de explicações factuais (empíricas) sobre os fenômenos psíquicos. (Fulgencio, 2003, p. 157)

Creio que isto tudo mostra que o uso de construções auxiliares é, para Freud, um fundamento metodológico de construção da psicanálise como ciência natural. Instrumento que, quero a seguir mostrar, pode ser reconhecido como uma orientação metodológica específica do programa kantiano de pesquisa a priori para as ciências da natureza.

\section{O programa de pesquisa kantiano e as especulações ${ }^{6}$}

No final da Crítica da razão pura, Kant determina o lugar a ser dado à psicologia, tomada como ciência natural:

o seu lugar é aquele onde deve ser colocada a física propriamente dita (empírica), isto é, do lado da filosofia aplicada, para a qual a filosofia pura contém os princípios a priori e com a qual, portanto, deve estar unida, mas não confundida. (Kant, 1787/1997, B 876)

Para Kant, a construção da psicologia empírica depende da admissão de um conjunto de conceitos e princípios a priori (que são também os da física empírica) a partir do qual todo conhecimento válido da natureza poderá ser produzido. Ou seja, é justamente a partir desse conjunto [de] a priori - relacionado a cada uma das faculdades que compõem nossa faculdade cognitiva (intuição, entendimento e razão) - que os cientistas vão à procura das leis que regem os fenômenos.

Kant mostrou que, por trás de toda ciência natural, há uma metafísica da natureza que a sustenta:

A ciência da natureza propriamente assim chamada pressupõe uma metafísica da natureza; com efeito, leis, isto é, princípios da necessidade do que é inerente à exis-

6 Esta análise do programa de pesquisa kantiano se apóia em Loparic, em seu trabalho $A$ semântica transcendental de Kant. Cf. Loparic (2000 [1982]). Esse item retoma uma análise já feita em Fulgencio 2003. 


\title{
Leopoldo Fulgencio
}

\begin{abstract}
tência de uma coisa, se referem a um conceito que não se pode construir, porque a existência não pode representar-se em nenhuma intuição a priori. Por conseguinte, a genuína ciência natural pressupõe uma metafísica da natureza. Esta deve, pois, conter sempre puros princípios, que não são empíricos (é por isso que leva o nome de metafísica). (Kant, 1786/1990, p. 15; A 7-8)
\end{abstract}

Não é cabível, aqui, fazer uma apresentação mais completa do programa de pesquisa kantiano para as ciências naturais. Saliento apenas uma de suas características principais, relativa ao uso de princípios e conceitos especulativos, relacionada à metafísica da natureza presente no quadro teórico de toda ciência empírica; por conseguinte, também da psicanálise tal como Freud a concebeu.

Tendo analisado a arquitetura e o funcionamento de nossa faculdade de conhecer, Kant distinguiu três modos distintos de articular o conhecimento: a intuição ou a sensibilidade, o entendimento e a razão. Nos três, sempre encontramos conceitos e princípios a priori; para alguns deles, será possível encontrar os referentes empíricos adequados, enquanto, para outros, tal possibilidade estará excluída. À sensibilidade ou à intuição - com seus a priori do espaço e do tempo - caberá fornecer dados intuitivos para o entendimento. Ao entendimento - com seus conceitos a priori, suas categorias ${ }^{7} \mathrm{e}$ os dados que recebe da intuição (percepção) - caberá a constituição daquilo a que chamamos experiência e seus objetos, fornecendo regras para a exposição dos fenômenos. Cabe também ao entendimento procurar as leis gerais que regem os fenômenos assim apreendidos. Por fim, à razão credita-se a tarefa de fornecer princípios e conceitos que dêem sistematicidade aos juízos do entendimento e proporcionar a maior extensão possível para esse conhecimento teórico. Kant chamará esses conceitos puros da razão de idéias (cf. Kant, 1787/1997, B 367396); estas jamais terão um referente empírico que lhes corresponda adequadamente, pois se referem a entes da razão, nunca a realidades empíricas (nem mesmo em hipótese):

7 As categorias (ou conceitos puros do entendimento) foram organizadas por Kant em quatro classes: as que reúnem os conceitos a priori relativos à quantidade, na qual estão os conceitos de unidade, pluralidade e totalidade; as relativas à qualidade, na qual estão os conceitos de realidade, negação e limitação; as relativas à relação, na qual estão os conceitos de substância e acidentes, causa e efeito, reciprocidade causal; e as relativas à modalidade, com os conceitos de possibilidade e impossibilidade, existência e não-existência, necessidade e contingência. 
Fundamentos Kantianos da Psicanálise Freudiana e o Lugar da Metapsicologia...

\begin{abstract}
Os conceitos da razão... são meras idéias e não têm, evidentemente, objeto algum em qualquer experiência, mas não designam por isso objetos imaginados e ao mesmo tempo admitidos como possíveis. São pensados de modo meramente problemático $^{8}$, para fundar em relação a eles (como ficções heurísticas) princípios reguladores do uso sistemático do entendimento no campo da experiência. Se sairmos deste campo, são meros seres da razão, cuja possibilidade não é demonstrável e que não podem também, por hipótese, ser postos como fundamento da explicação dos fenômenos reais. (Kant, 1787/1997, B 799)
\end{abstract}

A compreensão do lugar da especulação na pesquisa científica depende, pois, do entendimento da função e da operação da razão especulativa, ou seja, trata-se de saber o que são, quais são e como operam essas idéias da razão. Utilizarei alguns exemplos para esclarecer a função e a natureza dos conceitos puros da razão. Um desses conceitos é a idéia de natureza como um todo. Sua função é designar um pressuposto para que as leis de determinação entre os fenômenos façam parte de um mesmo sistema, e sua natureza é totalmente especulativa; trata-se de um conceito que não pode ser exemplificado com nenhum dado empírico. Outra idéia da razão pura - que diz respeito diretamente à maneira como Freud opera na construção da teoria psicanalítica - está relacionada com um problema que a própria razão encontra ao tentar fornecer explicações sistemáticas, as mais completas possível, para os fenômenos que ela procura conhecer, ou seja, quando a razão procurar estabelecer a série de causas, finitas e sem lacunas, para explicar algum fenômeno ou movimento na natureza ${ }^{9}$ uma vez dado um efeito qualquer, sempre é possível remetê-lo à sua causa; assim sendo, essa causa, por sua vez, pode, igualmente, ser remetida a uma outra causa anterior; o que acaba por estabelecer uma série infinita. Kant nos diz que a razão, visando interromper essa pesquisa infinita das causas, estabelece um limite, postulando uma causa originária, anterior à qual nenhuma outra deve ser procurada; uma causa incondicionada que não precisa ser explicada e a partir da qual todas as relações causais devem ser estabelecidas. Essa causa originária é um ente da razão e não advém, pois, da experiência sensível: o que seria impossível, já que não corresponde a uma entidade fenomênica. Ela é apenas uma convenção.

8 Kant diz: "Chamo problemático a um conceito que não contenha contradição e que... se encadeia com outros conhecimentos, mas cuja realidade objetiva não pode ser de maneira alguma conhecida" (Kant, 1787/1997, B 310).

9 Cf. Kant (1787/1997, B 377-389) para a explicação de Kant sobre a natureza e a função das idéias transcendentais. 


\section{Leopoldo Fulgencio}

Também em Princípios metafísicos a toda ciência da natureza, um conjunto de conceitos e princípios a priori necessários a toda ciência da natureza, Kant mostra que a razão, ante a necessidade de fornecer explicações causais finitas e sem lacunas, estabelece um ponto de partida para as causas, postulando uma causa originária ou incondicionada. Ele diz, ainda, que existem duas alternativas básicas para conceber essas causas, ou seja, apenas dois pontos de vista-guia para explicar a "diversidade específica das matérias" e suas relações: o mecânico e o dinâmico. Segundo o ponto de vista mecânico ou atomista, o movimento, na natureza, deveria ser explicado em função de partículas indivisíveis, os átomos. Estes seriam responsáveis pela transmissão do movimento entre os corpos, por choque mecânico. Já o ponto de vista dinâmico suporia, com o mesmo fim, que o movimento deve ser explicado em função de forças motrizes agindo na matéria e no encontro entre os corpos. Segundo Kant, não se trata de supor infinitas forças, o que apenas obscureceria o entendimento, mas, sim, de considerar apenas duas forças básicas: as de atração e as de repulsão.

Tanto os átomos como as forças são conceitos puros ( a priori) elaborados pela razão, portanto não podem ser confundidos com os dados empíricos: não há apreensão sensível possível nem dos átomos nem das forças. Como é que se decide, então, por um ou outro ponto de vista como orientação de pesquisa? Segundo Kant, trata-se de uma escolha que não pode estar baseada em fatos, mas tão-somente nos frutos que um ou outro pode render para a pesquisa empírica. O ponto de vista dinâmico, diz Kant, é "muito mais adequado e favorável" (Kant, 1786/1990, p. 83; A 102) para atingir uma explicação sistêmica mais extensa e mais conforme à razão, permitindo encontrar leis determinadas num encadeamento racional, sem que seja necessário supor alguma "qualidade oculta", tal como é necessário quando se supõem "átomos" como transmissores de movimento. Como diz Loparic, o critério de escolha entre um ou outro ponto de vista é apenas heurístico:

Tudo o que ele [Kant] disse é que a teoria dinâmica, se julgada por alguns critérios metodológicos razoáveis, é um melhor guia de pesquisa empírica do que a teoria atomista. Essa é uma avaliação do ponto de vista heurístico de ambas as teorias tal como existiam na sua época, que de modo algum pode ser interpretada como uma tentativa de uma dedução a priori da teoria dinâmica. (Loparic, 2000, p. 315) 
Fundamentos Kantianos da Psicanálise Freudiana e o Lugar da Metapsicologia...

Em resumo, a noção de natureza, o ponto de vista dinâmico e as forças são conceitos puros da razão, idéias que não têm referente possível no mundo sensível; são idéias que têm entes da razão como referentes e que servem como guias de pesquisa factual.

Não é, pois, por acaso que Freud caracteriza as pulsões como idéias abstratas, conceitos puramente convencionais. Ele sabe que o preenchimento do seu conteúdo só poderá ocorrer de forma inadequada, pois não há referente empírico possível para elas. Ao usar o termo Trieb, Freud retoma um termo comum à filosofia e à ciência alemã pós-kantiana, que está na base de sua formação como homem de ciência (cf. Loparic, 1999). Não seria correto dizer que o conceito freudiano de Trieb corresponde exatamente às forças motrizes das quais fala Kant, mas a maneira como Freud opera teoricamente, na formulação do conceito de pulsão, tem não só uma proximidade com o lugar que Kant dá aos conceitos puros da razão, como também obedece ao mesmo tipo de necessidade metafísica que caracteriza as ciências naturais no programa de pesquisa kantiano.

Pode-se dizer que a psicanálise foi construída nesse solo da metafísica da natureza do tipo kantiana, considerando que a vida da alma deveria ser tomada como um objeto natural (Freud, 1933a, p. 159). Objeto determinado, então, por relações de causa e efeito, tais como as que são dadas pelas categorias do entendimento, aplicáveis a esses objetos. Nesse sentido, de acordo com o programa kantiano, os fenômenos psíquicos (objetos dados ao sentido interno) e seus movimentos deveriam ser explicados a partir do ponto de vista dinâmico.

\section{Proximidade entre a metapsicologia freudiana e a metafísica da natureza kantiana}

A psicanálise, tal como Freud a concebeu, é composta, então, por dois tipos de teoria. Um que abriga esse conjunto de conceitos especulativos que funcionam como ficções, conceitos que não têm, pois, referente possível no campo factual, cuja validade é apenas heurística; conjunto teórico que Freud denominou, no seu sentido estrito, de metapsicologia. E um segundo tipo de teoria, composto por conceitos que têm referente no campo dos fatos, tal como apreendidos na clínica pelo método de investigação e tratamento que é a psica- 


\section{Leopoldo Fulgencio}

nálise, conjunto de conceitos dentre os quais estão os que Freud caracterizou, em 1923, como sendo os fundamentos empíricos da psicanálise, a saber, cito Freud referindo-se aos Pilares da Teoria Psicanalítica:

A hipótese de processos anímicos inconscientes ${ }^{10}$, o reconhecimento da doutrina da resistência e da repressão [Verdrängung], o valor dado à sexualidade e ao Complexo de Édipo são os conteúdos principais da psicanálise e os fundamentos de sua teoria, e quem não está à altura de subscrever todos eles não deveria se considerar psicanalista. (p. 247)

Esses fundamentos empíricos da psicanálise não parecem ser propriamente uma novidade para a filosofia. Para indicar apenas uma dessas características mais centrais, a consideração de que existem idéias e processos psíquicos inconscientes já está, para retomar Kant, presente explicitamente no parágrafo 5 do Antropologia do ponto de vista pragamático, onde Kant se refere às representações obscuras (aliás, algo já notado por Pontalis no seu artigo "ISSO em letras maiúsculas", de 1997). O que parece mesmo ter sido a grande invenção de Freud é a compreensão desses fatos (processos psíquicos inconscientes, a importância da sexualidade e do complexo de Édipo, a importância e a influência da relação médico-paciente) em função de um método de tratamento psíquico (ou seja, tratamento por meios psíquicos: a palavra e a relação médico-paciente) que se mostrava eficiente na resolução de problemas clínicos não resolvíveis por outros métodos.

Assim, gostaria de concluir que a metapsicologia freudiana - com seus conceitos de pulsão, libido e aparelho - se constitui de ficções heurísticas que tornam possível a Freud tomar a vida psíquica como um objeto tal qual qualquer outro estrangeiro ao homem, fazendo da psicanálise uma proposta de psicologia empírica no quadro das ciências da natureza, a qual, por sua vez, tem o mesmo tipo de causalidade apresentada por Kant no seu programa de pesquisa a priori ou, noutros termos, na sua metafísica da natureza, causalidade que é uma das categorias do entendimento.

10 Faço aqui uma distinção entre o reconhecimento clínico dos processos anímicos inconscientes - o que também já havia sido feito por Charcot, Janet, Bernheim e Lipps, a quem Freud reconhece tributo, e que é claramente visível na análise que Freud faz dos atos falhos nas lições de 1916-17 - e o inconsciente pensado em termos metapsicológicos. Trata-se de diferenciar o inconsciente considerado num sentido factual de um inconsciente especulativo, tomado como uma instância psíquica atravessada por forças e energias. 
Fundamentos Kantianos da Psicanálise Freudiana e o Lugar da Metapsicologia...

É nesse sentido que a pergunta sobre a filosofia pós-Freud talvez deva ser recolocada inversamente, ou seja, trata-se de saber o que a filosofia pósKant, especialmente a filosofia do século XX, teria a dizer para essa psicanálise construída sobre o solo kantiano.

\section{A psicanálise pós-Freud e a possível transformação de seus aspectos ontológicos como um problema para a discussão filosófica}

Num outro sentido, considerando que a metapsicologia apresenta certos aspectos que se referem aos fundamentos metafísicos ou ontológicos da psicanálise, caberia perguntar sobre o desenvolvimento da metapsicologia pós-Freud e o que decorre daí para os problemas que cabem à filosofia.

Focando a questão no que se refere ao desenvolvimento da teoria metapsicológica pós-Freud, pode-se dizer que a metapsicologia teve três grandes destinos: o da sua reiteração e expansão (Abraham, Ferenchi, Klein), o da sua substituição por uma outra (Lacan e Bion), e o de seu abandono (Winnicott). ${ }^{11}$ Dentre estes, os dois últimos podem representar uma reformulação dos fundamentos ontológicos da psicanálise.

Podemos afirmar que Lacan propôs uma outra metapsicologia para a psicanálise. Mas creio poder afirmar também que, no seu retorno a Freud, ele reiterou a necessidade metodológica do uso de uma superestrutura especulativa.

Note-se, quanto a isso, que, no Livro I dos Seminários. Os escritos técnicos de Freud (1953-1954), Lacan se detém na importância do esquema óptico que ele denominou de "estádio do espelho":

O estádio do espelho, eu o tenho frisado, não é simplesmente um momento do desenvolvimento. Tem também uma função exemplar, porque revela certas relações do sujeito à sua imagem, enquanto Urbild do eu. Ora, esse estádio do espelho, impossível de denegar, tem uma apresentação óptica - tampouco se pode negar isso. Será, por acaso? (Lacan, 1975/1983, p. 91)

11 Ver em Assoun (2000) uma análise da situação da metapsicologia pós-Freud, e em Fulgencio (2006) um estudo sobre o abandono que Winnicott fez dos principais conceitos da metapsicologia freudiana. 


\section{Leopoldo Fulgencio}

Parece que Lacan se detém para explicar o valor epistemológico e metodológico desse tipo de esquema, afirmando, então, que isso faz parte das ciências em geral. Diz Lacan: "As ciências, e sobretudo as ciências em gestação como a nossa, freqüentemente tomam emprestado modelos de outras ciências" (Lacan, 1975/1983, p. 91). Isso não é para ele, no entanto, exatamente uma nova proposta dentro da psicanálise, mas um procedimento ditado por Freud: "Não estou, quanto a isso [figuração óptica, espacial, de fenômenos psíquicos], em desacordo com a tradição do mestre - mais de um entre vocês certamente observou, na Traumdeutung, no capítulo "Psicologia dos Processos do Sonho", o famoso esquema no qual Freud insere todo o processo inconsciente" (Lacan, 1975/1983, p. 91).

Lacan aprofunda sua análise mostrando, então, que, para Freud, não se trata de - na figuração do psiquismo como se fosse um aparelho - formular uma hipótese supondo que um dia seria encontrada a referência empírica de seu modelo, antes, essa hipótese especulativa tem a função de auxiliar na pesquisa, tal como um andaime auxilia a construção do edifício, mas não se confunde com ele, desde que, aconselha Freud, "não tomemos o andaime pelo próprio edifício".

Lacan, de bom humor, afirma assim sua opção metodológica para o desenvolvimento da teoria psicanalítica:

Inútil dizer-lhes que, como os conselhos são dados para não serem seguidos, não deixamos desde então de tomar o andaime pelo prédio. Por outro lado, a autorização que Freud nos dá de utilizar relações auxiliares para nos aproximarmos de um fato desconhecido me incitou a dar provas de uma certa desenvoltura para construir um esquema. (Lacan, 1975/1983, p. 92)

A metapsicologia lacaniana apresenta uma série de novos pressupostos, conceitos e expressões - tais como a interrogação pelo desejo do outro, o outro como parte do sujeito, o sujeito do inconsciente, as noções de simbólico-real-imaginário, o ponto de vista estruturalista, o significante, o uso de esquemas, etc. -, os quais podem significar uma transformação nos aspectos ontológicos da psicanálise, ainda que Lacan tenha mantido a teorização do tipo metapsicológica como necessária para a psicanálise. Nesse sentido, suas proposições podem significar uma mudança parcial na ontologia da psicanálise, o que recolocaria aos filósofos a tarefa de analisar a ontologia e avaliar 
Fundamentos Kantianos da Psicanálise Freudiana e o Lugar da Metapsicologia...

como esses novos aspectos ontológicos propostos por Lacan podem contribuir para os problemas e objetivos da filosofia.

O terceiro destino da metapsicologia, ou seja, o seu abandono, tanto em termos de seus conteúdos como em termos da metodologia de pesquisa, uma vez que rejeita a opção pelo uso de superestruturas especulativas, também pode significar uma reformulação nos aspectos ontológicos da psicanálise. É esse o caso de Winnicott.

Note-se sua postura crítica em relação à metapsicologia, no que diz respeito a ser uma teoria especulativa, assim registrada na carta que envia a Anna Freud em 1954:

Estou tentando descobrir por que é que tenho uma suspeita tão profunda com esses termos [metapsicológicos]. Será que é por que eles podem fornecer uma aparência de compreensão onde tal compreensão não existe? Ou será que é por causa de algo dentro de mim? Pode ser, é claro, que sejam as duas coisas. (Winnicott, 1987, p. 51)

Um autor atento à obra de Winnicott, como é André Green, já notou que ele não usa o conceito de aparelho psíquico. Diz Green:

Freud defendeu a idéia de um aparelho psíquico. É fácil compreender por que a imagem de um instrumento para definir o psíquico parece desagradável e se choca com um ponto de vista humanista, e Winnicott nunca usa este construto. O ponto de vista de Freud negligencia a perspectiva dos relacionamentos, aparte aqueles estabelecidos neste aparelho. (Green, 2005, p. 13)

Green não está de acordo com o abandono desse conceito ${ }^{12}$, mas isso não é relevante para o momento, pois se trata aqui de mostrar o que fez Winnicott e não as teorias de Green, ou, ainda, o julgamento que Green faz de Winnicott.

Noutro lugar, mostrei com mais detalhes como Winnicott abandonou

12 Sem tirar nenhuma conseqüência da posição de Winnicott, Green simplesmente afirma, sem mais, sua posição na defesa da noção (da sua noção) de aparelho psíquico: "Eu gostaria de defender a idéia de um aparelho de um ponto de vista abstrato - é muito difícil defendê-lo epistemologicamente, mas, dentro da organização teórica de Freud, o conceito de um aparelho permite enfatizar que a mente, como o cérebro, dividida em diferentes formações filogenéticas, não é uma estrutura unificada, mas dividida em diferentes "instâncias" em conflito, em relacionamentos antagônicos e agonísticos” (Green, 2005, p. 13). 


\title{
Leopoldo Fulgencio
}

os conceitos fundamentais da metapsicologia freudiana - o conceito de pulsão, de aparelho psíquico e de libido - a favor de um outro tipo de teorização que não é uma especulação em termos de forças ou esquemas para pensar a natureza humana, mas uma tentativa de descrição conceitual e objetiva da natureza humana, que pode encontrar na experiência factual seus referentes.

É assim que a obra de Winnicott, além de rejeitar a metapsicologia, introduz pressupostos, conceitos, termos e expressões (tais como necessidade de ser, tendência inata à integração, solidão essencial, o ser como advindo do não-ser, elaboração imaginativa, chegar à via, si-mesmo originário, inconsciente originário e inconsciente reprimido como dois tipos de inconsciente, os diversos sentidos do termo realidade - subjetiva, transicional e objetivamente dada ou percebida -, etc.) que são uma transformação nos aspectos ontológicos da psicanálise; logo, um relançar de propostas e problemas que caberá à filosofia discutir no seu próprio campo de pesquisa.

No desenvolvimento de uma análise como esta, seria necessário, então, retomar fundamentos ontológicos que estariam na base da psicanálise proposta por Lacan e na da proposta por Winnicott, relançado a pergunta sobre o que a psicanálise teria a dizer para a filosofia ou, no sentido inverso, o que a filosofia teria a dizer para a psicanálise.

Por ora, isso extrapolaria o quadro aqui apresentado, no qual o que me parece crucial, dado o desenvolvimento que fiz até aqui, é a exposição dos aspectos kantianos presentes em Freud, na sua invenção da psicanálise.

Fulgencio, L. (2007). Kantian foundations of Freudian Psychoanalysis and the place of metapsychology in the development of psychoanalysis. Psicologia USP, 18(1), 37-56.

\begin{abstract}
This study intends to show that Freud's references to Kant do not refer to specific points or themes, but that Freud constructed psychoanalysis in an effort to elaborate a scientific psychology following Kant's a priori research program for natural sciences. This program not only objectified psychism, such as any other matter strange to human beings, making it natural, but also proposed that this subject be researched with the help of specific heuristic fictions - particularly those that
\end{abstract}


Fundamentos Kantianos da Psicanálise Freudiana e o Lugar da Metapsicologia...

characterize the supposition of forces in conflict, from the dynamic point of view - which, finally, characterize meta-psychological theorization in psychoanalysis. Such a perspective raises the question of the future of post - Freudian psychoanalysis; given that Kantian philosophical ground has suffered severe criticisms with the development of post-Kantian philosophy.

Index terms: Freud, Sigmund. Kant, Immanuel. Philosophy of science. Metaphysics. Psychoanalysis and philosophy.

Fulgencio, L. (2007). Les fondements de la théorie kantienne chez Freud et la métapsychologie dans le développement de la psychanalyse. Psicologia USP, 18(1), 37-56.

Résumé: Je prétends soutenir que les références de Freud à Kant ne concernent pas seulement à des points ou sujets spécifiques, étant donné que Freud a construit la psychanalyse dans la tentative d'élaborer une psychologie scientifique conformément au programme de Kant pour la recherche a priori des sciences de la nature. Ce programme fait l'objetification du psychisme comme a toute autre chose étrangère à l'homme, en le naturalisant, et il propose aussi que cet objet soit recherché avec l'aide de fictions heuristiques - en particulier celles qui constituent l'hypothèse de forces qui sont en conflit, forces qui caractérisent le point de vue dynamique -, lesquelles, en dernière instance, caractérisent la théorisation du type metapsichologique dans la psychanalyse. Ces considérations posent des questions sur l'avenir de la psychanalyse pósFreud, vu que le sol philosophique defendu par Kant a souffert sévères critiques dès le développement de la philosophie pós-Kant.

Mots-clés: Freud, Sigmund. Kant, Immanuel. Philosophie de la science. Métaphysique. Psychanalyse et philosophie.

\section{Referências}

Assoun, P-L. (2000). La métapsychologie. Paris: PUF.

Green, A. (2005). Winnicott at the Start of the Third Millennium. In L. Cadwell (Ed.), Sex and sexuality. Winnicottian perspectives. London: Karnac. 


\section{Leopoldo Fulgencio}

Freud, S. (1894). The neuron-psychoses of defense. In S. Freud, Standard edition of the complete psychological works of Sigmund Freud (Vols. 3, J. Strachey, trad.). London: The Hogarth Press.

Freud, S. (1900). The interpretation of dreams. In S. Freud, Standard edition of the complete psychological works of Sigmund Freud (Vols. 4-5, J. Strachey, trad.). London: The Hogarth Press.

Freud, S. (1911). Psycho-analytic notes on an autobiographical account of a case of paranoia (Dementia Paranoides). In S. Freud, Standard edition of the complete psychological works of Sigmund Freud (Vol. 12, J. Strachey, trad.). London: The Hogarth Press.

Freud, S. (1911-12). Totem and Taboo. In S. Freud, Standard edition of the complete psychological works of Sigmund Freud (Vols. 13, J. Strachey, trad.). London: The Hogarth Press.

Freud, S. (1913). On psycho-analysis. In S. Freud, Standard edition of the complete psychological works of Sigmund Freud (Vol. 12, J. Strachey, trad.). London: The Hogarth Press.

Freud, S. (1915a). Instincts and their vicissitudes. In S. Freud, Standard edition of the complete psychological works of Sigmund Freud (Vol. 14, J. Strachey, trad.). London: The Hogarth Press.

Freud, S. (1915b). The unconscious. In S. Freud, Standard edition of the complete psychological works of Sigmund Freud (Vol. 14, J. Strachey, trad.). London: The Hogarth Press.

Freud, S. (1916). Introductory lectures on psycho-analysis. In S. Freud, Standard edition of the complete psychological works of Sigmund Freud (Vol. 15-16, J. Strachey, trad.). London: The Hogarth Press.

Freud, S. (1920). Beyond the pleasure principe. In S. Freud, Standard edition of the complete psychological works of Sigmund Freud (Vols. 18, J. Strachey, trad.). London: The Hogarth Press.

Freud, S. (1923). Two encyclopaedia articles. In S. Freud, Standard edition of the complete psychological works of Sigmund Freud (Vol. 18, J. Strachey, trad.). London: The Hogarth Press.

Freud, S. (1924). The economic problem of masochism. In S. Freud, Standard edition of the complete psychological works of Sigmund Freud (Vols. 19, J. Strachey, trad.). London: The Hogarth Press.

Freud, S. (1925). An autobiographical study. In S. Freud, Standard edition of the complete psychological works of Sigmund Freud (Vol. 20, J. Strachey, trad.). London: The Hogarth Press. 
Fundamentos Kantianos da Psicanálise Freudiana e o Lugar da Metapsicologia...

Freud, S. (1933a). New introductory lectures on psycho-analysis. In S. Freud, Standard edition of the complete psychological works of Sigmund Freud (Vol. 22, J. Strachey, trad.). London: The Hogarth Press.

Freud, S. (1933b). Why war? In S. Freud, Standard edition of the complete psychological works of Sigmund Freud (Vol. 22, J. Strachey, trad.). London: The Hogarth Press.

Freud, S. (1940). An outline of psycho-analysis. In S. Freud, Standard edition of the complete psychological works of Sigmund Freud (Vol. 23, J. Strachey, trad.). London: The Hogarth Press.

Fulgencio, L. (2001). Comentários críticos das referências textuais de Freud a Kant. Psicologia USP, 12(1), 49-87.

Fulgencio, L. (2003). As especulações metapsicológicas de Freud. Natureza Humana, 5(1), 129-73.

Fulgencio, L. (2004). O projeto como uma metáfora biológica dos processos psíquicos. Psicologia USP, 14(3), 117-135.

Fulgencio, L. (2007). Winnicott's rejection of the basic concepts of Freud's metapsychology. The International Journal of Psychoanalysis, 88, 443-61.

Heidegger, M. (2001). Seminários de Zollikon. Petrópolis, RJ: Educ/ABD/Vozes. (Trabalho original publicado em 1987)

Kant, I. (1990). Princípios metafísicos da ciência da natureza. Lisboa: Edições 70. (Trabalho original publicado em 1786)

Kant, I. (1997). Crítica da razão pura. Lisboa: Fundação Calouste Gulbenkian. (Trabalho original publicado em 1787)

Lacan, J. (1983). Seminários. Livro 1. Os escritos técnicos de Freud 1953-1954. Rio de Janeiro: Zahar. (Trabalho original publicado em 1975)

Loparic, Z. (1999). O conceito de Trieb no filosofia e na psicanálise. In J. A. T. Machado (Ed.), Filosofia e psicanálise: um dialogo. Porto Alegre: EDIPCRS.

Loparic, Z. (2000). A semântica transcendental de Kant. Campinas: CLE.

Loparic, Z. (2001). Theodor Lipps: uma fonte esquecida do paradigma freudiano. Natureza humana, 3 (1), 315-31.

Loparic, Z. (2003a). As duas metafísicas de Kant. Kant e-Prints, 2(5). Recuperado de http:// www.cle.unicamp.br/kant-e-prints

Loparic, Z. (2003b). De Kant a Freud: um roteiro. Natureza Humana, 5(1), 231-245.

Mach, E. (1922). La conaissance et l'erreur. Paris: Flammarionn. (Trabalho original publicado em 1905) 


\section{Leopoldo Fulgencio}

Pontalis, J.-B. (1997). ISSO em letras maiúsculas. Percurso, 12(23), 5-15.

Popper, K. (1957). Ciência: conjecturas e refutações. In K. Popper, Conjecturas e refutações (O Progresso do Conhecimento Científico). Brasília: Ed. da Universidade de Brasília.

Winnicott, D. (1987). O gesto espontâneo. São Paulo: Martins Fontes.

Recebido em: 11/01/2007

Aceito em: 12/02/2007 